\title{
Pengembangan Implementasi DSS Aplication Penentuan Level Kondisi Anak Penyandang Disabilitas Tunanetra Menggunakan Metode AHP
}

\author{
Herlan Sutisna $^{1}$, Miftah Farid Adiwisastra ${ }^{2,}$ Ai Ilah Warnilah ${ }^{3}$ \\ ${ }^{1}$ Universitas Bina Sarana Informatika \\ herlan.her@bsi.ac.id \\ ${ }^{2}$ Universitas Bina Sarana Informatika \\ miftah.mow@bsi.ac.id \\ ${ }^{3}$ Universitas Bina Sarana Informatika \\ ai.aiw@bsi.ac.id
}

\begin{abstract}
Abstrak - Komunikasi dan teknologi sekarang sangat berkembang pesat yang menghasilkan informasi guna mempermudah pekerjaan manusia, teknologi smartphone yang sangat pesat, terkadang belum dimaksimalkan dalam bentuk aplikasi yang menunjang pendidikan. Aplikasi Pendukung keputusan merupakan salah satu alternatif yang potensial untuk mendukung kegiatan pendidikan, yang berdampak pada tingkat keberhasilan guru dalam proses belajar mengajar, pada dasarnya kebutuhan penyandang disabilitas tidak berbeda dengan kebutuhan manusia pada umumnya. Disabilitas bukanlah penghalang seseorang untuk memperoleh pendidikan yang terbaik, Kondisi tunanetra diasumsikan berimplikasi pada aspek mental, fisik dan psikis. Aspek tersebut perlu diatasi melalui metode dan media yang disesuaikan dengan kondisi dan potensi anak tersebut, permasalahan yang terjadi banyak sekolah atau guru yang menuntut anak bisa mengikuti pembelajaran tanpa peduli dengan kemampuan yang dimiliki siswa tersebut. Kurangnya pemahaman guru tentang kemampuan yang dimiliki peserta didik dapat menghambat proses pembelajaran. Peneliti merancang Aplikasi Mobile sistem pendukung keputusan penentuan level kondisi anak penyandang disabiltas tunanetra agar mempercepat Informasi Level Kondisi Anak tersebut dengan implementasi metode AHP dalam pengolahan datanya dengan kriteria Tingkat Ketunanetraan, Masa Ketunanetraan, Kondisi Mental, Kondisi Psikologis, dan Intelektual. Hasil penelitian dengan perhitungan metode AHP dalam pengolahan nilai kriterianya, maka hasil yang diperoleh 0.489783991 bisa menjadi rekomendasi bagi guru untuk menerapkan kurikulum Reguler (Konversi K13) untuk anak didiknya.
\end{abstract}

Keywords: Sistem Pendukung Keputusan, Aplikasi Mobile, Android, Disabilitas, Tunanetra

Abstract - Communication and technology are now very rapidly producing information to facilitate human work, smartphone technology is very fast, sometimes it has not been maximized in the form of applications that support education. Decision support applications are one of the potential alternatives to support educational activities, which have an impact on the success rate of teachers in the teaching and learning process, basically the needs of persons with disabilities are no different from the needs of humans in general. Disability is not a barrier for a person to get the best education, visually impaired conditions are assumed to have mental, physical and psychological implications.These aspects needed to be addressed through methods and media that were adapted to the condition and potential of the child,The problems that occur were many schools or teachers who required children to take part in learning without caring about the abilities of these students.The teacher's lack of understanding of the abilities of students could hinder the learning process. The researchers designed a mobile application for a decision support system to determine the level of the condition of children with visual impairments in order to speed up the information on the level of the child's conditionwith the implementation of the AHP method in data processing with the criteria for the level of blindness, period of blindness, mental conditions, psychological conditions, and intellectuals. The results of the study by calculating the AHP method in processing the criteria value then the results obtained 0.489783991 can be a recommendation for teachers to implement the Regular curriculum (K13 Conversion) for their students

Keywords: Decision Support System, Mobile Application, Android, Disabilities, visually impaired

\section{PENDAHULUAN}

Pada dasarnya kebutuhan penyandang disabilitas tidak berbeda dengan kebutuhan manusia pada umumnya, begitupun dalam hal pendidikan. Kelainan bukanlah penghalang seseorang untuk memperoleh pendidikan, (Lestari et al., 2015)
"Pendidikan merupakan hak semua warganegara, tak terkecuali bagi warganegara yang memiliki kelainan fisik, emosional, mental, intelektual dan/atau sosial, yang berhak memperoleh pendidikan khusus". para penyandang disabilitas berhak untuk memperoleh pendidikan dalam rangka 
pemenuhan kebutuhannya. ((UNICEF), 2013) Hal tersebut dikarenakan "anak-anak penyandang disabilitas berpotensi untuk menjalani kehidupan secara penuh dan berkontribusi pada vitalitas sosial, budaya, dan ekonomi dari masyarakat mereka". Untuk memenuhi kebutuhan tersebut, sekolah atau lembaga pendidikan harus menyiapkan program pemenuhan kebutuhan dalam bentuk kurikulum yang sesuai dengan tingkat kebutuhan siswa. Anak penyandang Tunanetra memiliki kondisi indera penglihatan yang tidak berfungsi secara keseluruhan. Kondisi tersebut diasumsikan berimplikasi pada aspek mental, fisik dan psikis anak tunanetra. menurut (Blackhurst,Edward A. Berdine William, 1981)"dari segi kecerdasan sebagian besar tunanetra tidak dipengaruhi oleh ketunaannya, kecuali bagi mereka yang mengalami kelaianan ganda (double handicaped), Hanya saja tunantera mengalami kesulitan untuk pembentukan ataupun penerimaan gagasan yang bersifat abstrak." Hal tersebut perlu diatasi melalui metode dan media yang disesuaikan dengan kondisi dan potensi anak tunanetra.

Kurikulum di Sekolah Luar Biasa pada umumunya bisa digolongkan sebagai Bidang Studi dan juga sebagai keterampilan khusus, begitupun dengan SLB Bina Harapan Bangsa. Secara keseluruhan kurikulum dan program tersebut memiliki tujuan untuk meniadakan atau mengurangi hambatan belajar bagi anak yang menyadang disabilitas khususnya Tunanetra, dan membantu mereka untuk memahami atau menyadari akan potensi dan kemampuan yang dimilikinya. PrinsipPrinsip Pembelajaran untuk Anak Tunanetra salah satunya adalah Prinsip Individual yaitu prinsip yang sama dalam pembelajaran, baik untuk Pendidikan Luar Biasa atau Pendidikan Umum, seorang guru dituntut untuk mengobservasi dan memperhatikan adanya perbedaan-perbedaan pada setiap individu. (Ishartiwi, 1991) "Pemberian layanan pendidikan bagi tunanetra sangat tergantung dari kondisi berat atau ringannya kelainan yang disandang". Untuk Pendidikan yang diperuntukan tunanetra, maka perbedaan individu yang satu dengan individu yang lainnya menjadi lebih luas dan kompleks. Dalam hal pasti adanya perbedaan-perbedaan umum seperti Kesehatan, Kemampuan Mental, usia, Sosial, fisik, budaya, dan selain perbedaan perbedaan umum tersebut, terdapat juga sejumlah perbedaan khusus terkait dengan tunanetra yang disandangnya, diantaranya tingkat ketunanetraan, masa atau waktu terjadinya kecacatan, penyebab ketunanetraan, dampak sosial-psikologis akibat ketunanetraaannya. (Hamidi, 2016) "Paradigma masyarakat, terhadap kaum disabilitas seringkali diibaratkan sebagai ketidakmampuan seseorang secara medis, sehingga disabilitas dianggap sebagai orang sakit yang selalu membutuhkan pertolongan dan tidak dapat mengenyam pendidikan".
(Lestari et al., 2015) Pendidikan merupakan hak semua warganegara, tak terkecuali bagi warga negara yang memiliki kelainan fisik, emosional, mental, intelektual dan/atau sosial, yang berhak memperoleh pendidikan khusus. Salah satu implementasinya adalah berupa kebijakan dari dinas pendidikan kabupaten/kota yang menyarankan sekolah reguler siap sedia memberikan program inklusi jika memiliki siswa Inklusi atau berkebutuhan khusus, salah satunya adalah siswa inklusi kesulitan belajar. Permasalahan yang sering dihadapi dalam penetapan siswa inklusi adalah saat menyelenggarakan proses belajar mengajar, "kepala sekolah bersama dengan guru-guru harus memilih dan menetapkan peserta didik yang patut mendapatkan pendidikan inklusi sesuai dengan kriteria yang telah ditetapkan"(Lestari et al., 2015). Saat ini penilaian dari setiap kriteria belum menggunakan suatu metode keputusan, sehingga penilaian antar peserta masih menggunakan prediksi atau perkiraan yang dapat menimbulkan penilaian bersifat subyektif. Dampak lebih lanjut dari permasalahan tersebut yaitu menimbulkan kurang tepatnya pemilihan siswa inklusi. Dengan perkembangan teknologi informasi yang mencakup segala bidang, perlu dirancang sebuah sistem yang dapat membantu dalam penetapan siswa inklusi kesulitan belajar, agar dapat membantu mempermudah pihak sekolah dalam menyeleksi dan menetapkan siswa inklusi kesulitan belajar, sehingga hasil yang diinginkan tepat sasaran dan sesuai dengan kriteria yang telah ditetapkan. Hal tersebut dapat terbantu dengan sistem pendukung keputusan penetapan siswa inklusi kesulitan belajar menggunakan metode Analitycal Hierarcy Process (AHP) yang mampu membantu memecahkan persoalan yang kompleks menjadi lebih sederhana dan mempercepat proses pengambilan keputusan. Dalam hal pelayanan pendidikan yang akan diberikan kepada penyandang tunanetra, maka terdapat beberapa perbedaan metode pendidikan antara anak yang mengalami Buta total dengan anak Low Vision dan juga perbedaan khusus yang disandangnya, Hal ini mengisyaratkan perlunya seorang guru untuk merancang strategi pembelajaran kepada anak sesuai dengan kondisi anak tersebut.

Dalam pelaksanaan proses pendidikan, sering kali siswa dituntut untuk dapat mengikuti kurikulum yang ada atau yang diberikan oleh gurunya, tanpa peduli dengan kemampuan yang dimiliki siswa tersebut, apakah murid bisa mengikutinya atau tidak. Kurangnya pemahaman pendidik tentang kemampuan yang dimiliki dan kebutuhan yang diperlukan peserta didik dapat menghambat proses pembelajaran, oleh karna itu seorang guru harus mampu mencari cara untuk mengetahui apa yang dibutuhkan peserta didik. Untuk Menentukan metode pembelajaran, guru harus melakukan 
identifikasi siswa dengan mengambil keputusan berdasarkan kriteria-kriteria yang muncul pada peserta didik tersebut, dengan demikian maka diperlukan sebuah sistem yang bisa memberikan sebuah ouput atau informasi yang bisa menjadi masukan dan rekomendasi bagi guru untuk menentukan level kondisi anak berdasarkan kriteria-kriteria yang ada, sehingga hal ini bisa mempengaruhi terhadap metode pembelajaran yang tepat bagi peserta didik sesuai dengan level kondisi anak. Penggunaan metode AHP sebagai pengolahan datanya untuk menentukan metode pembelajaran sesuai dengan level kondisi anak.

Penelitian yang dilakukan oleh (Dave, n.d.). Dalam peneltiannya memaparkan Bentuk dan keakuratan setiap bagian yang dikerjakan menggunakan proses pemesinan elektro tergantung terutama pada bentuk dan keakuratan pahat atau elektroda pemotong. Oleh karena itu, pemilihan elektroda alat dalam Proses Pengerjaan Pelepasan Elektro menjadi tugas penting. Secara teoritis, setiap bahan yang merupakan konduktor listrik yang baik dapat digunakan sebagai alat dengan berbagai keuntungan. Sangat sulit untuk menemukan bahan tunggal yang memiliki semua karakteristik yang diinginkan, dan karenanya pemilihan menjadi tugas yang sulit. Makalah ini mengusulkan metodologi yang didasarkan pada Analytic Hierarchy Process (AHP) untuk pemilihan Tool Electrode untuk Proses Machining Discharge Electro. Berdasarkan metode AHP, Indeks Seleksi Elektroda (ESI) ditemukan untuk semua alternatif yang dipertimbangkan dalam penelitian ini. ESI ini membantu untuk mengevaluasi dan memberi peringkat sejumlah bahan alternatif yang diberikan. Hasil penelitian ini menunjukkan bahwa Graphite dan Copper adalah bahan terbaik untuk membuat alat elektroda dalam proses EDM.

Selanjutnya penelitian yang dilakukan oleh (Jain \& Rao, 1936) dalam penelitiannya menjelaskan Permintaan untuk tanaman obat dan eksploitasi mereka di seluruh dunia telah mendorong lembaga internasional seperti Organisasi Kesehatan Dunia (WHO) dan departemen kesehatan nasional seperti AYUSH untuk fokus pada pemanfaatan berkelanjutan. Namun, kurangnya metodologi pengambilan keputusan menyulitkan pengusaha pedesaan untuk mendirikan bisnis. Makalah ini telah mengembangkan templat Pembuatan Keputusan Multi-Kriteria, menggunakan Analytic Hierarchy Process (AHP), yang memberi peringkat teknologi terbaik untuk ekstraksi sembilan tanaman obat yang tumbuh di Ghats Barat India. Tanaman ini memiliki lebih dari $20 \%$ subsidi dalam budidaya di bawah NMMP dan memiliki properti anti kanker. Teknologi yang dipilih untuk AHP adalah agitasi / sentrifugasi, ekstraksi pelarut dingin, ekstraksi refluks / soxhlet, perkolasi dingin, ekstraksi berbantuan gelombang mikro, sonikasi dan ekstraksi pelarut panas. Kemampuan alat untuk menyediakan pemilihan teknologi ekstraksi dengan fleksibilitas proses seperti pemilihan kriteria, pemilihan teknologi dan bobot kriteria memungkinkan penggunaannya oleh pengusaha pedesaan, fasilitator teknologi, evaluator proposal pengusaha pedesaan dan pembuat kebijakan.

(Schwarz, n.d.) dalam penelitiannya Urutan di mana insinyur layanan di bidang manajemen layanan TI memutuskan untuk menyelesaikan insiden sangat penting mengingat dampaknya pada kinerja bisnis penyedia layanan TI. Solusi yang mungkin untuk mengurangi dampak negatif adalah mendukung teknisi layanan melalui sistem pendukung keputusan yang menghitung prioritas untuk insiden berdasarkan dampak bisnis mereka. Mempertimbangkan prioritas ini dalam keputusan mereka, insinyur layanan dapat membantu mengurangi dampak negatif tersebut pada bisnis penyedia layanan TI. Tujuan dari penelitian ini adalah untuk memasukkan metode Analytical Hierarchy Process (AHP) ke dalam perangkat perangkat lunak untuk memprioritaskan insiden sesuai dengan keparahan dampak bisnis mereka. Akibatnya, sistem pendukung keputusan yang disebut Incident Prioritizer (IP) dikembangkan. Ini menggunakan metode AHP untuk menghitung prioritas untuk insiden berdasarkan kriteria khas yang relevan di bidang manajemen layanan TI untuk menilai dampak bisnis dari insiden. Kriteria ini biasanya ditentukan oleh manajemen organisasi penyedia layanan TI, dan mencerminkan pemahaman manajemen tentang dampak bisnis yang disebabkan oleh insiden. Hasil menunjukkan bahwa metode AHP dapat berhasil diterapkan untuk masalah yang diberikan prioritas insiden. Prioritas ini difasilitasi oleh model keputusan AHP yang hanya terdiri dari satu tingkat kriteria dan mempertimbangkan penilaian dari manusia serta data dari sistem informasi eksternal.

(Mary, 2014)menuturkan dalam penelitiannya Latar belakang penelitian ini adalah dalam menemukan metode pembelajaran berbasis komputer yang khusus digunakan untuk mata kuliah praktikum komputer terutama yang berbasiskan bahasa pemrograman komputer. Hal tersebut dilatar belakangi kesulitan Mahasiswa dalam memahami mata kuliah pratikum yang berbasiskan bahasa pemrograman komputer. Teori dan modul praktikum yang telah diberikan, melalui empiris masih belum cukup dalam menunjang keberhasilan Mahasiswa memahaminya, hal ini bukan berarti mata kuliah praktikum terlalu sulit untuk dipahami, namun bisa saja karena berbagai aspek seperti : kurangnya minat dalam membaca, memahami dan mempraktekan modul, terlalu takut dengan matematika yang ada dalam bahasa pemrograman komputer, ataupun dari metode-metode pembelajaran yang digunakan. Untuk itulah penelitian ini memfokuskan kepada metode pembelajaran yang terbaik dan efektif untuk mendapatkan pemahaman terhadap perkuliahan praktikum yang berbasiskan bahasa pemrograman 
komputer. Dalam memilih metode pembelajaran terbaik, terlebih dahulu merangkum kriteria-kriteria serta alternatif-alternatif metode pembelajaran yang mendukung keberhasilan. Penentuan tersebut haruslah yang mampu menerapkan serta mengaplikasikan multi kriteria dan multi alternatif yang dihitung secara terstruktur dan memiliki tingkat kesalahan yang sangat kecil, adapun cara yang digunakan adalah dengan metode Analytic Hierarchy Process (AHP) yang ada dalam aplikasi software Super Decisions. Semua kriteria dan alternatif unggulan akan dibobot serta dirangking baik dengan tabel maupun dengan grafik. Hasil dari proses AHP adalah bobot final yang disertai dengan perangkingan kriteria dan alternatif sehingga menghasilkan alternatif (metode pembelajaran) terbaik yang mendapatkan bobot prioritas tertinggi. Alternatif yang memiliki bobot tertinggi digunakan sebagai bahan pendukung pengambilan keputusan bagi Dosen pengampu mata kuliah praktikum berbasiskan bahasa pemrograman komputer untuk diaplikasikan".

\section{METODOLOGI PENELITIAN}

1. Analytical Hierarchy Process (AHP)

Perancangan Aplikasi menggunakan metode AHP dalam pengolahan data kriteria kriterianya, diantaranya tingkat ketunanetraan, masa ketunanetraan, kondisi mental, kondisi psikologi dan intelektual, yang selanjutya akan diimplemntasikan dikoding, dan dengan metode waterfall dalam pengembangan aplikasinya. dimulai dari analisis, desain, pengkodean, pengujian dan tahap pendukung (support) berikut penjelasan dari setiap tahapan menurut (Sukamto \& Salahuddin, 2013)

1) Analisis Kebutuhan /Requirements

Tahapan ini akan dilakukan proses pengumpulan kebutuhan yang akan digunakan oleh user serta mendokumentasikan semua spesifikasi kebutuhan tersebut.

2) Design

Memiliki beberapa desain tahapan dalam membuat program diantaranya struktur data, arsitektur perangkat lunak, representasi antarmuka, serta prosedur pengkodean. Setiap desain akan didokumentasikan.

3) Pengkodean dan Implementasi

Desain yang sudah dibuat diatas selanjutnya ditranslasikan ke dalam program perangkat lunak. Hasilnya adalah program komputer yang sesuai dengan desain yang telah dibuat sebelumnya.

4) Pengujian dan verifikasi

Tahap ini memastikan bahwa setiap bagian perangkat lunak berjalan dari segi logika dan fungsionalitas nya serta memastikan keluaran yang dihasilkan sesuai dengan yang diinginkan. Serta untuk meminimalisir kesalahan (error) dari program.
5) Pendukung / Support dan Maintennance Ditahap ini tidak menutup kemungkinan mengulangi proses pengembangan mulai dari analisis dikarenakan adanya perubahan yang diakibatkan oleh kesalahan yang muncul dan tidak terdeteksi sebelumnya saat tahap pengujian.

2. Perancangan Penelitian

Penelitian ini menggunakan penelitian eksperimen, yaitu penelitian yang melibatkan penyelidikan perlakuan pada parameter atau variabel tergantung dari penelitinya dan menggunakan tes yang dikendalikan oleh si peneliti itu sendiri, dengan langkah yang dilakukan dalam metode penelitian.

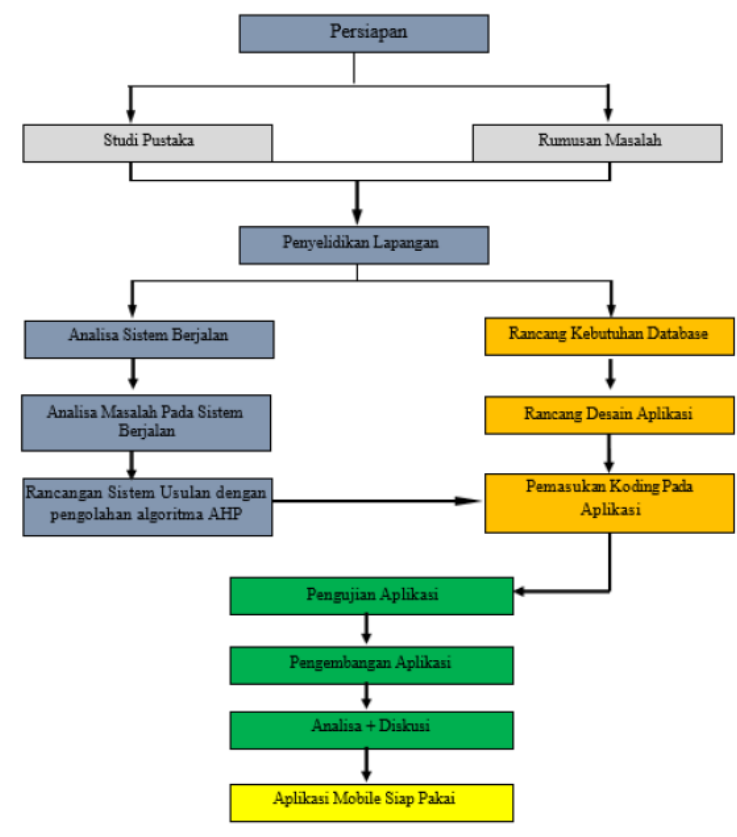

Gambar 1. State of the Art Penelitian Sumber: (Sutisna, Adiwisastra, \& Warnilah, 2020)

\section{HASIL DAN PEMBAHASAN}

1. Prosedur Sistem Berjalan

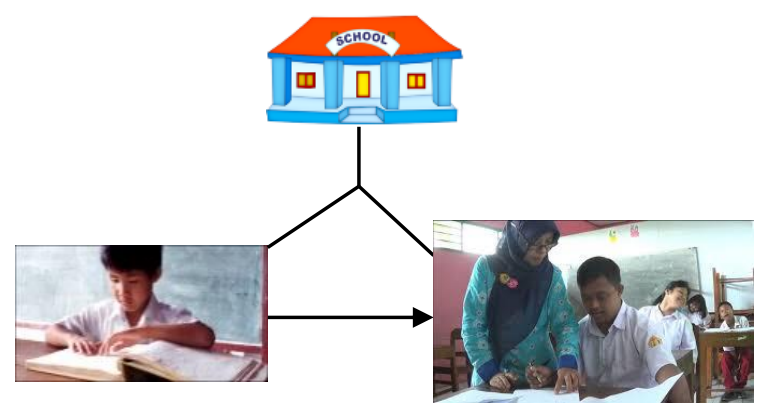

Gambar 2. Pengajaran Sistem Berjalan Sumber: (Sutisna et al., 2020) 
2. Sistem Usulan

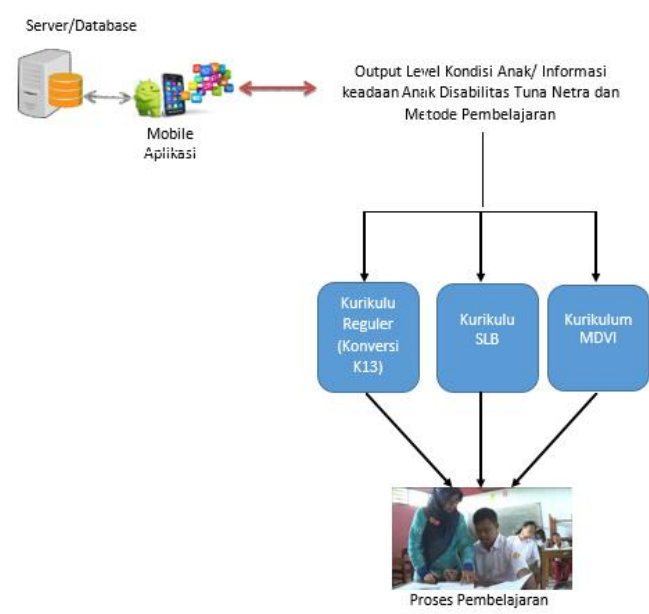

Gambar 3. Sistem Usulan

Sumber: (Sutisna et al., 2020)

3. Rancangan Kebutuhan Database

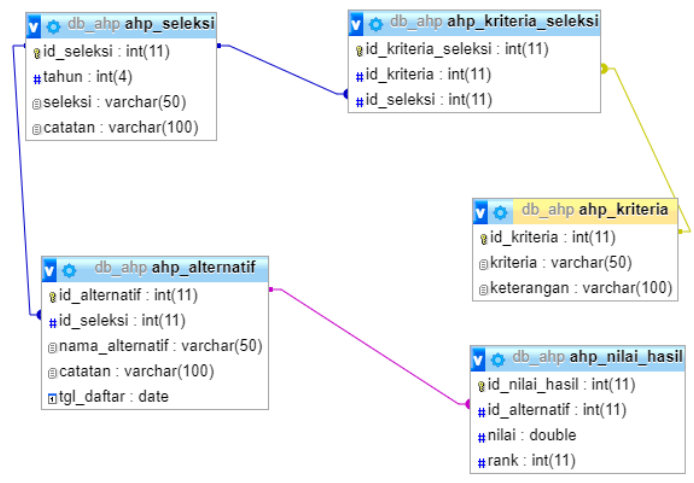

Gambar 4. Sistem Usulan

Sumber: (Sutisna et al., 2020)

\section{Desain Aplikasi}

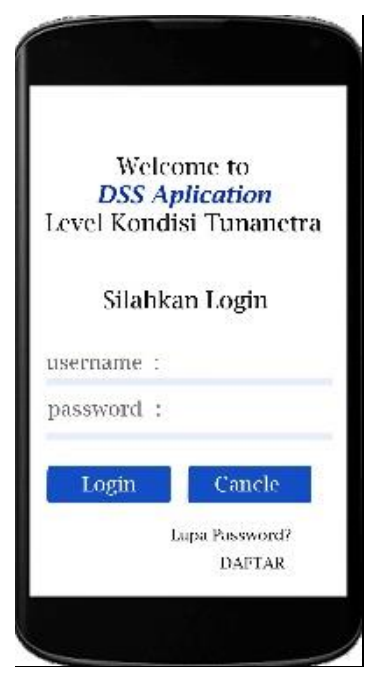

Sumber: (Sutisna et al., 2020)

Gambar 5. Halaman Awal

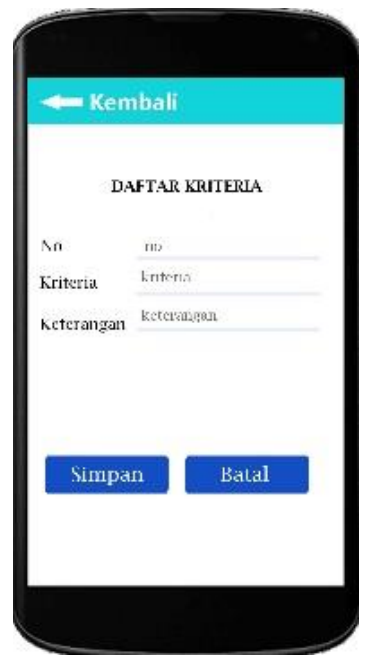

Sumber: (Sutisna et al., 2020)

Gambar 6. Daftar Kriteria

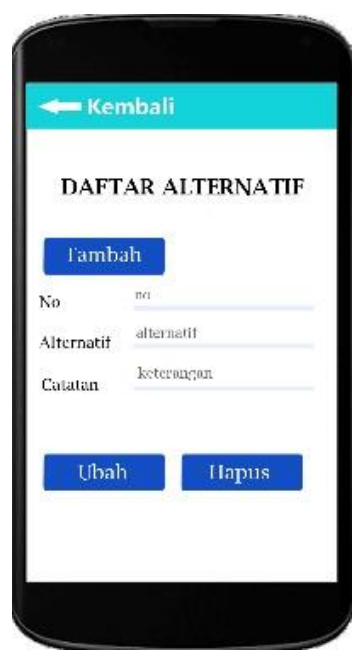

Sumber: (Sutisna et al., 2020)

Gambar 7. Daftar Alternatif

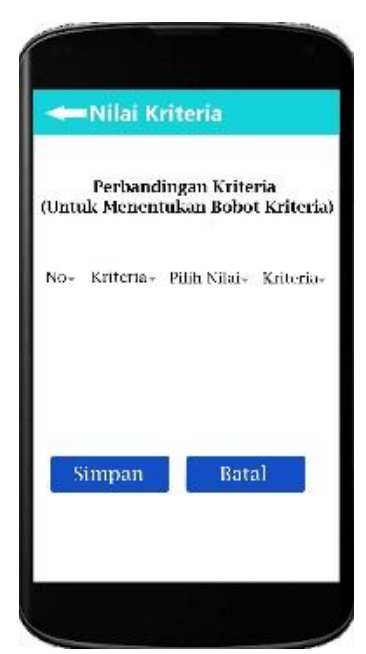

Sumber: (Sutisna et al., 2020)

Gambar 8. Nilai Kriteria 


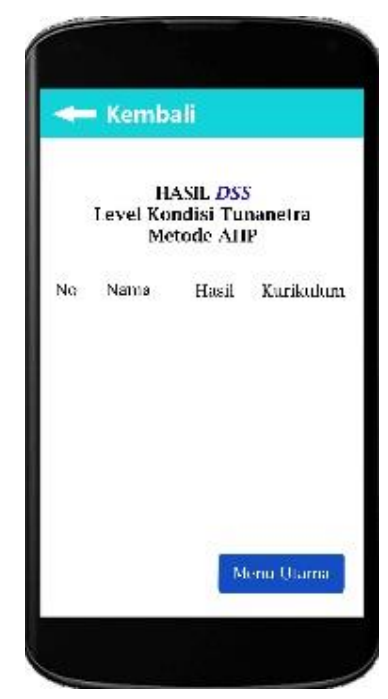

Sumber: (Sutisna et al., 2020)

Gambar 9. Halaman Hasil

5. Penyusunan Prinsip Penyusunan Hirarki

Tingkat teratas pada hirarki adalah fokus atau tujuan. Sedangkan tingkat dibawahnya adalah kriteria. Apabila masih bisa dipecah maka tingkat selanjutnya dinamakan sub kriteria, dan seterusnya sampai tingkatan akhir yang merupakan alternatif-alternatif yang akan dipilih. Berikut adalah bentuk struktur hirarki:

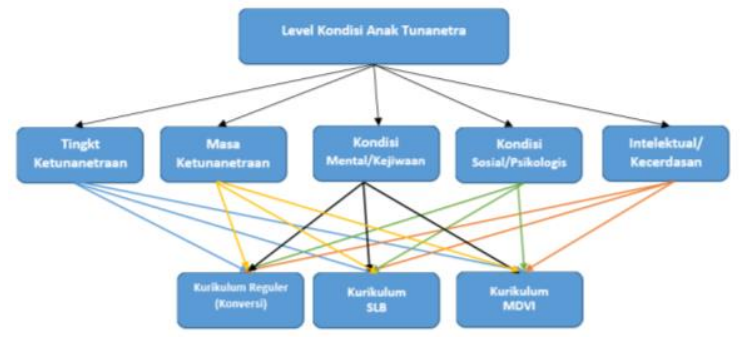

Sumber: (Sutisna et al., 2020)

Gambar 10. Halaman Hasil

6. Penentuan Kriteria dan Alternatif

Kriteria yang digunakan dalam perhitungan AHP dalam penelitian ini adalah :

a) Aspek Tingkt Ketunanetraan yaitu Buta Total atau low Vision

b) Aspek Masa Ketunanetraan yaitu sejak lahir atau sudah dewasa

c) Aspek Kondisi Mental/Kejiwaan yaitu Baik atau Kurang Baik

d) Aspek Kondisi Sosial/Psikologis yaitu Baik atau kurang baik

e) Aspek Intelektual/Kecerdasan yaitu dibawah rata-rata, Normal atau diatas rata-rata
Tabel 1. Matrik Pairwise Comparison Level Kriteria Berdasarkan Tujuan

\begin{tabular}{l|c|c|c|c|c|}
\hline \multicolumn{1}{|c}{$\begin{array}{c}\text { Tingk } \\
\text { t } \\
\text { Ketujuan } \\
\text { anetra } \\
\text { an }\end{array}$} & $\begin{array}{c}\text { Masa } \\
\text { Ketun } \\
\text { anetra } \\
\text { an }\end{array}$ & $\begin{array}{c}\text { Kondisi } \\
\text { Mental/Kej } \\
\text { iwaan }\end{array}$ & $\begin{array}{c}\text { Kondisi } \\
\text { Sosial/Psi } \\
\text { kologis }\end{array}$ & $\begin{array}{c}\text { Intele } \\
\text { ktual/ } \\
\text { Kecer } \\
\text { dasan }\end{array}$ \\
\hline $\begin{array}{l}\text { Tingkt } \\
\text { Ketunanetr } \\
\text { an }\end{array}$ & 1.00 & 2.00 & 7.00 & 7.00 & 3.00 \\
\hline $\begin{array}{l}\text { Masa } \\
\text { Ketunanetr } \\
\text { aan }\end{array}$ & 0.50 & 1.00 & 3.00 & 3.00 & 3.00 \\
\hline $\begin{array}{l}\text { Kondisi } \\
\text { Mental/Ke } \\
\text { jiwaan }\end{array}$ & 0.14 & 0.33 & 1.00 & 3.00 & 0.33 \\
\hline $\begin{array}{l}\text { Kondisi } \\
\text { Sosial/Psik } \\
\text { ologis }\end{array}$ & 0.14 & 0.33 & 0.33 & 1.00 & 0.33 \\
\hline $\begin{array}{l}\text { Intelektual } \\
\text { /Kecerdasa } \\
\text { n }\end{array}$ & 0.33 & 0.33 & 3.00 & 3.00 & 1.00 \\
\hline & 2.12 & 4.00 & 14.33 & 17.00 & 7.67 \\
\hline Sumber: & & & & & \\
\hline
\end{tabular}

Sumber: (Sutisna et al., 2020)

Tabel 2. Selisih Nilai Eigen

\begin{tabular}{|c|c|c|c|c|c|c|c|}
\hline \multicolumn{6}{|c|}{ Nilai Eigen } & \multirow{2}{*}{$\begin{array}{c}\mathrm{Jml} \\
2.26\end{array}$} & \multirow{2}{*}{$\begin{array}{c}\begin{array}{c}\text { Rt- } \\
\text { rt }\end{array} \\
0.45\end{array}$} \\
\hline $\begin{array}{l}\text { Tingkt } \\
\text { Ketunanetraan }\end{array}$ & 0.47 & 0.50 & 0.49 & 0.41 & 0.39 & & \\
\hline $\begin{array}{l}\text { Masa } \\
\text { Ketunanetraan }\end{array}$ & 0.24 & 0.25 & 0.21 & 0.18 & 0.39 & 1.26 & 0.25 \\
\hline $\begin{array}{l}\text { Kondisi } \\
\text { Mental/Kejiwaan }\end{array}$ & 0.07 & 0.08 & 0.07 & 0.18 & 0.04 & 0.44 & 0.09 \\
\hline $\begin{array}{l}\text { Kondisi } \\
\text { Sosial/Psikologis }\end{array}$ & 0.07 & 0.08 & 0.02 & 0.06 & 0.04 & 0.28 & 0.06 \\
\hline $\begin{array}{l}\text { Intelektual/ } \\
\text { Kecerdasan }\end{array}$ & 0.16 & 0.08 & 0.21 & 0.18 & 0.13 & 0.76 & 0.15 \\
\hline \multicolumn{7}{|c|}{ Jumlah } & 1.00 \\
\hline
\end{tabular}

Sumber: (Sutisna et al., 2020)

7. Hasil Cek Nilai Konsistensi

$\mathrm{CI}=($ lamda Max-n $) /(\mathrm{n}-1)$

Lamda Max

: 5.332260442

CI

: 0.08306511

$\mathrm{CR}=\mathrm{CI} / \mathrm{IR} \quad: 0.074$

Hasil perhitungan CR menunjukan angka 0.074 itu berarti hasilnya adalah KONSISTEN Karena CR kurang dari 0,1 maka hasil dapat diterima

Dalam studi kasus yang diambil dari SLB Bina Harapan Bangsa diperoleh data kriteria sebagai berikut atas nama Fadhil:

Tingkat Ketunanetraan : Total

Masa Ketunanetraan : Sejak Lahir

Kondisi Mental/Kejiwaan : Baik

Kondisi Sosial/Psikologis : Baik

Intelektual/Kecerdasan : Normal 
Tabel 3.Matrik Perbandingan Kriteria Tingkat

\begin{tabular}{|l|c|c|c|}
\hline & $\begin{array}{c}\text { Kurikulum } \\
\text { Reguler } \\
\text { (Konversi } \\
\text { K13) }\end{array}$ & Kurikulum SLB & $\begin{array}{c}\text { Kurikulum } \\
\text { Fungsional } \\
\text { MDVI }\end{array}$ \\
\hline $\begin{array}{l}\text { Kurikulum Reguler } \\
\text { (Konversi K13) }\end{array}$ & 1.00 & 3.00 & 2.00 \\
\hline Kurikulum SLB & 0.33 & 1.00 & 0.33 \\
\hline $\begin{array}{l}\text { Kurikulum } \\
\text { Fungsional MDVI }\end{array}$ & 0.50 & 3.00 & 1.00 \\
\hline & 1.83 & 7.00 & 3.33 \\
\hline
\end{tabular}

Sumber: (Sutisna et al., 2020)

Tabel 4. Matrik Perbandingan Kriteria Masa Ketunanetraan

\begin{tabular}{|l|c|c|c|}
\hline & $\begin{array}{c}\text { Kurikulum } \\
\text { Reguler } \\
\text { Konversi } \\
\text { K13) }\end{array}$ & Kurikulum SLB & $\begin{array}{c}\text { Kurikulum } \\
\text { Fungsional } \\
\text { MDVI }\end{array}$ \\
\hline $\begin{array}{l}\text { Kurikulum Reguler } \\
\text { (Konversi K13) }\end{array}$ & 1.00 & 3.00 & 2.00 \\
\hline Kurikulum SLB & 0.33 & 1.00 & 0.33 \\
\hline $\begin{array}{l}\text { Kurikulum } \\
\text { Fungsional MDVI }\end{array}$ & 0.50 & 3.00 & 1.00 \\
\hline & 1.83 & 7.00 & 3.33 \\
\hline
\end{tabular}

Sumber: (Sutisna et al., 2020)

Tabel 5. Matrik Perbandingan Kriteria Kondisi Mental/Kejiawaan

\begin{tabular}{|l|c|c|c|}
\hline & $\begin{array}{c}\text { Kurikulum } \\
\text { Reguler } \\
\text { Konversi } \\
\text { K13) }\end{array}$ & Kurikulum SLB & $\begin{array}{c}\text { Kurikulum } \\
\text { Fungsional } \\
\text { MDVI }\end{array}$ \\
\hline $\begin{array}{l}\text { Kurikulum Reguler } \\
\text { (Konversi K13) }\end{array}$ & 1.00 & 0.50 & 3.00 \\
\hline Kurikulum SLB & 2.00 & 1.00 & 3.00 \\
\hline $\begin{array}{l}\text { Kurikulum } \\
\text { Fungsional MDVI }\end{array}$ & 0.33 & 0.33 & 1.00 \\
\hline & 3.33 & 1.83 & 7.00 \\
\hline
\end{tabular}

Sumber: (Sutisna et al., 2020)

Tabel 6. Matrik Perbandingan Kriteria Sosial/Psikologis

\begin{tabular}{|l|c|c|c|}
\hline & $\begin{array}{c}\text { Kurikulum } \\
\text { Reguler } \\
\text { (Konversi } \\
\text { K13) }\end{array}$ & Kurikulum SLB & $\begin{array}{c}\text { Kurikulum } \\
\text { Fungsional } \\
\text { MDVI }\end{array}$ \\
\hline $\begin{array}{l}\text { Kurikulum Reguler } \\
\text { (Konversi K13) }\end{array}$ & 1.00 & 0.50 & 0.50 \\
\hline Kurikulum SLB & 2.00 & 1.00 & 0.50 \\
\hline $\begin{array}{l}\text { Kurikulum } \\
\text { Fungsional MDVI }\end{array}$ & 2.00 & 2.00 & 1.00 \\
\hline & 5.00 & 3.50 & 2.00 \\
\hline
\end{tabular}

Sumber: (Sutisna et al., 2020)
Tabel 7. Matrik Perbandingan

KriteriaIntelektual/Kecerdasan

\begin{tabular}{|l|c|c|c|}
\hline & $\begin{array}{c}\text { Kurikulum } \\
\text { Reguler } \\
\text { (Konversi } \\
\text { K13) }\end{array}$ & Kurikulum SLB & $\begin{array}{c}\text { Kurikulum } \\
\text { Fungsional } \\
\text { MDVI }\end{array}$ \\
\hline $\begin{array}{l}\text { Kurikulum Reguler } \\
\text { (Konversi K13) }\end{array}$ & 1.00 & 3.00 & 2.00 \\
\hline Kurikulum SLB & 0.33 & 1.00 & 0.33 \\
\hline $\begin{array}{l}\text { Kurikulum } \\
\text { Fungsional MDVI }\end{array}$ & 0.50 & 3.00 & 1.00 \\
\hline & 1.83 & 7.00 & 3.33 \\
\hline
\end{tabular}

Sumber: (Sutisna et al., 2020)

Untuk menghitung CI dan CR sama dengan perhitungan kriteria yang hasilnya harus kurang dari 0.1 agar hasilnya konsisten atau dapat diterima.

Hasil Perengkingan berdasarkan perhitungan AHP, dan kriteri yang dimiliki calon siswa SLB Bina Harapan Bangsa

Tabel 8. Hasil Perengkina

\begin{tabular}{|l|c|c|}
\hline \multicolumn{3}{|c|}{ Perangkingan } \\
\hline $\begin{array}{l}\text { Kurikulum Reguler (Konversi } \\
\text { K13) }\end{array}$ & 0.489783991 & 1 \\
\hline Kurikulum SLB & 0.184721949 & 3 \\
\hline Kurikulum Fungsional MDVI & 0.32549406 & 2 \\
\hline
\end{tabular}

Sumber: (Sutisna et al., 2020)

Hasil perhitungan menunjukan dengan kriteria yang dimiliki maka kurikulum yang direkomendasikan yaitu kurikulum Reguler (Konversi K13) dimana kurikulum ini merupakan kurikum yang sama dengan kurikulum untuk sekolah reguler namun dengan modifikasi atau konversi agar bisa dipahami dan dimengerti siswa tunanetra.

\section{KESIMPULAN}

Peneliti merancang Aplikasi Mobile sistem pendukung keputusan penentuan level kondisi anak penyandang disabiltas tunanetra agar mempercepat Informasi Level Kondisi Anak tersebut dengan implementasi metode AHP dalam pengolahan datanya dengan kriteria Tingkat Ketunanetraan, Masa Ketunanetraan, Kondisi Mental, Kondisi Psikologis, dan Intelektual. Dari hasil perhitungan dengan menggunakan metode AHP dalam pengolahan nilai kriterianya, maka hasil yang diperoleh 0.489783991 bisa menjadi rekomendasi bagi guru untuk menerapkan kurikulum Reguler (Konversi K13) untuk anak didiknya. 


\section{REFERENSI}

(UNICEF), U. N. C. F. (2013). Keadaan Anak Di Dunia 2013.

Blackhurst Edward A. - Berdine William. (1981). An introduction to Special Education. New York: Little Brown Company.

Dave, H. K. (n.d.). A Decision Support System For Tool Electrode Selection For Electro Discharge Machining Process Using The Analytic Hierarchy Process, 4(2), 89-103.

Hamidi, J. (2016). Perlindungan Hukum terhadap Disabilitas dalam Memenuhi Hak Mendapatkan Pendidikan dan Pekerjaan, 23(4), 652-671.

Ishartiwi. (1991). Keefektifan Penggunaan Media Audio (Tolking Book) dalam Kegiatan Belajar Tunanetra. IKIP malang.

Jain, R., \& Rao, B. (1936). Application Of AHP Tool For Decision Making Of Choice Of Technology For Extraction Of Anti- Cancer Bioactive Compounds Of Plant Origin, 5(1), 3-29.

Lestari, N., Studi, P., Informatika, T., Lancang, U., Inklusi, S., \& Belajar, K. (2015). Sistem penunjang keputusan penetapan siswa inklusi kesulitan belajar di sekolah dasar, 71-81.

Mary, T. (2014). Sistem Pendukung Keputusan Menggunakan Metode Analytic Hierarchy Process ( AHP ) Pemilihan Metode Pembelajaran untuk Mata Kuliah Praktikum yang Berbasiskan Bahasa Pemrograman Komputer Jurnal Edik Informatika, 1, 23-29.

Schwarz, C. (n.d.). Decision Support In It Service Management : Applying Ahp Methodology To The Itil Incident Management Process, 7(1), 104-120.

Sukamto, R., \& Salahuddin, M. (2013). Rekayasa Perangkat Lunak Terstruktur dan Berorientasi Objek. Bandung: Informatika.

Sutisna, H., Adiwisastra, M. F., \& Warnilah, A. ilah. (2020). Laporan Akhir Penelitian: Pengembangan Implementasi DSS Aplication Penentuan Level Kondisi Anak Penyandang Disabilitas Tunanetra Menggunakan Metode AHP. Tasikmalaya. https://doi.org/https://doi.org/10.31294/p.v21i 2

\section{PROFIL PENULIS}

Herlan Sutisna, S.T, M.Kom Merupakan Dosen di Fakultas Teknologi dan Informatika di Universitas Bina Sarana Informatika, berpengalaman mengajar sejak 2012 sampai dengan sekarang, aktif melaksanakan Tri Dharma, yaitu Pendidikan dan pengajaran, Penelitian dan Pengabdian kepada masyarakat, dan saat ini sudah meraih Sertifikasi Dosen.

\section{UCAPAN TERIMAKASIH}

Peneliti mengucapkan terimakasih kepada pihak Ristekdikti yang telah mendanai penelitian ini sampai selesai, dengan No SK:079/SP2H/LT/DRPM/2020 